to the industrial situation, but the conclusion reached from the study of the effects of long-term oral or parenteral administration of drugs should not necessarily be accepted as applicable to manufacturers or users in industry where the main route of entry is by inhalation or skin absorption. Nevertheless, the methods of evaluation of a drug for carcinogenicity and the principles to be applied for its safe use are similar to the methods and principles which apply to the evaluation and use of a possible carcinogen in industry.

Much information lies hidden in the increasing mass of literature on the subject of carcinogenesis. This book is the result of an attempt to collect and present it in a form which can be examined and assessed by those who are not experts but who are interested in the subject. That it succeeds only partially is not the fault of the contributors or of the editor, Professor Truhaut. It stems from the fact that there is too much complicated material to be encompassed in a meeting of this type or duration, or in a book of this size. Nevertheless, the authors and the editor have succeeded in getting much into small bulk and in presenting it with a commendable degree of clarity.

T. S. ScotT

Roe, F. J. C. (1965). The relevance of preclinical assessment of carcinogenesis. Clin. Pharm. Ther., 7, 77.

Decompression of Compressed Air Workers in Civil Engineering. Proceedings of an International Working Party held at the Ciba Foundation, London, October, 1965. Edited by R. I. McCallum. (Pp. xxi + 329; 47 figs.; 3 I tables; 42s.) Newcastle and London: Oriel Press. 1967.

This is the first book to be devoted to the particular problems discussed and the first book for more than 50 years to be published on aspects of caisson disease in compressed air workers. Since the classic works of Heller, Mager, and von Schrötter and of Leonard Hill, the emphasis has been on the related, but nevertheless distinct, problems of aviation and diving. From these adjoining fields the medical practitioner has learned much which he has applied to the particular problems of the compressed air worker, and, in return, the present study of man working in compressed air continues the invaluable flow of ideas and knowledge to those in these separate but related fields. Thus this book can be regarded as indispensable for those concerned with the prevention and treatment of all types of decompression sickness.

It is important to recognize that decompression from raised environmental pressures is becoming increasingly common both from under the sea and from compressed air, both nationally and throughout the world.The person who has worked in compressed air or as a diver may appear in any surgery or clinic. Thus these topics are important to an increasing number of medical practitioners and, of course, to all concerned with industrial medicine.

The International Working Party was primarily concerned at this meeting with an assessment of the decompression procedures used by compressed air workers in different countries and, in particular, the prevention of decompression sickness in both its acute form and its delayed form-aseptic necrosis of bone. This book forms the edited proceedings of this conference which was attended by a small number of selected experts representing nine countries, all actively engaged in work at raised environmental pressures. Thus, in a series of papers, the current views on decompression procedures and their physiological basis, the effectiveness of the different decompression tables, the manifestations of decompression sickness, their prevention and treatment are presented by each group in turn. From these detailed reports emerges a composite picture which shows very well the present state of knowledge as well as defining those areas in which more work is required, particularly if the crippling complications of caisson disease of bone are to be prevented.

A criticism that a considerable amount of the discussions, which are presented in a lively verbatim manner at the end of each chapter, could, for greater clarity, have been incorporated into the text or into a brief summary does not detract from the value of this book as a whole. There is no doubt that the publication of these proceedings is an important contribution to this and related fields and that the information presented at this conference should be studied by all who are concerned with this unique, challenging, and important aspect of occupational medicine.

\section{H. ElliotT}

The Year Book of Orthopaedics, Traumatic and Plastic Surgery. (I966-67 Year Book Series). Edited by H. Herman Young and Ned Owens. (Pp. 444; illustrated; 76s.) Chicago: Year Book Medical Publishers. r967.

This book is one of the Practical Medicine Year Books in which detailed abstracts of the important papers in the international medico-scientific literature are made available to specialists in different fields. As in all such volumes, the importance of the editor's selection of papers cannot be overemphasized. In this book there is a wide variety of abstracts in all three subjects of the title. Orthopaedic and Traumatic Surgery are grouped together, and there is a separate section on Plastic Surgery. From the point of view of a specialist in industrial medicine, the number of papers which could be regarded as having a direct bearing on his subject may not appear to be large. In the Orthopaedic and Traumatic Surgery section there are papers on the injuries produced by careless use of the highpressure airless spray gun, on bone lesions in compressed air workers, with particular reference to the building of the Clyde Tunnels between 1953 and 1963 and on traumatic amputations. In the Plastic Surgery section there are a number of papers on the treatment of highvoltage electric and other types of burns, a paper on 'the crushed finger', and others on reconstruction after tendon injuries.

Apart from these, the book gives a very good review of the whole field covered, and the specialist in industrial medicine would find it useful to brush up his knowledge of many common disorders and some rare conditions; 
these are likely to be seen primarily by the orthopaedic, traumatic or plastic surgeons but may affect the efficiency of workers in any branch of industry or may cause anxiety by affecting members of workers' families. The practical approach of the book is helpful here, as it is possible to gain a better idea of the length of time likely to be required for adequate treatment. Even the section on experimental studies will prove of interest when examined from this point of view.

V. A. WHEBLE

A Guide to Ship Sanitation. By Vincent B. Lamoureux. (Pp. II9; illustrated; 20s.) Geneva: World Health Organization. 1967.

The World Health Organization and Vincent B. Lamoureux, formerly Sanitary Engineer Director, Office Chief Engineer, Department of Health, Education and Welfare, United States Public Health Service, who prepared the Guide, are to be congratulated on their excellent production, which has followed the other successful Guide to Hygiene and Sanitation in Aviation.

The purpose of this latter Guide was to show how protection against infection could be provided on a world-wide basis for crews and passengers on international flights and during stop-overs at airports. The present Guide to Ship Sanitation has aimed at showing the importance of standardization of sanitary measures to be taken in ships, both to safeguard the health of travellers and to prevent the spread of infection from one country to another.

Most countries invest their Health Administration with authority for the inspection and certification of ships touching their ports. Sanitary control is exercised in accordance with legislation which generally requires fresh potable water, adequate accommodation for crew and passengers, and measures for vector control together with certain provisions for inspection, fumigation, and disinfection if required. Legislation in this form is frequently based on the International Sanitary Regulations, which are concerned only with quarantinable diseases.

The Guide to Ship Sanitation bridges the gap between legal requirements and their application. It provides practical recommendations for such measures as the protection of potable water from contamination, the preservation of food, the safe disposal of waste, and the rat-proofing and de-ratting of ships.

All shipping companies of note maintain these standards at a high level through strict medical supervision, but there are many instances where greater improvements could be made, and in this respect both management and men, ashore and afloat, must be aware of what is best for the good of everyone.

It is to be hoped that the World Health Organization will now complete a further Guide for 'All Travellers Everywhere'.

R. M. HegGIE

Occupational Safety, Health and Welfare in the Woodworking Industries. (Pp. I69; Free.) Geneva: International Labour Office. 1967.

This is a report of a Tripartite Technical Meeting held in 1967. It covers a broad field of safety, health, and welfare in the woodworking industries.

There is a long review of safety and health procedures covering the whole broad field of those industries concerned with wood preservation and wood manufacture. The various processes from the preservation, through various plywood and board manufactures to the production of furniture, are covered in a detailed manner, and much useful technical detail is provided.

Comparative statistics of the safety records of these differing industries in a group of industrialized countries are presented. The value of these is very doubtful.

A general survey of welfare facilities in these industries is followed by a detailed technical account of the primary and secondary materials which are used. There are numerous tables relating to the commoner types of machines and long lists of hazardous or potentially hazardous materials likely to be encountered.

The work as a whole is extremely comprehensive and could be most useful as a work of reference to those facing problems which arise out of woodworking in general industry. Its telegraphic style and turgid translations do not make easy reading, but its broad coverage of the many problems of industries which have received too little attention makes it a valuable source book for anyone encountering their numerous problems.

W. T. JONES

Preventive Aspects of Occupational Health Nursing. By John F. Copplestone. (Pp. 120; 21s.) London: Edward Arnold. I967.

This work is attractively printed and is designed to complement the ground covered in standard textbooks of Occupational Health Nursing.

Its emphasis is on personal preventive nursing in industry, and it contains chapters on the problems of teenagers, women at work, the disabled worker, and ageing. There are introductory chapters dealing with broader aspects of occupational health nursing, such as health education techniques and the health interview. There is a short list of references and an adequate index.

The book fills a gap that has long existed in occupational health nursing, and the advice it gives is, for the most part, direct, relevant, and sound. The style is clear and the prose lucid.

Most senior nurses, and many doctors, will have learnt from years of experience, to practise the techniques and recognize the problems described, but for the younger nurses, and perhaps for many doctors entering industry, this work could become a standard text. In attempting to cover such a wide span of topics, the inevitable compression has resulted in some oversimplification. Perhaps this slightly dogmatic approach will help the younger nurse to see her way more clearly through an often bewildering set of problems.

For the students for whom it is intended, and for many senior people, the book can be thoroughly recommended. W. T. JONES

Organization of Occupational Health Services in Developing Countries. Report of the Fifth Session 